\title{
Inhibition of TPA-induced metastatic potential by morin hydrate in MCF-7 human breast cancer cells via the Akt/GSK-3ß/c-Fos signaling pathway
}

\author{
KYU-SHIK LEE, GI SUK NAM, JUNYOUNG BAEK, SOYOUNG KIM and KYUNG-SOO NAM \\ Department of Pharmacology, School of Medicine and Intractable Disease Research Center, \\ Dongguk University, Gyeongju, Gyeongsangbuk 38066, Republic of Korea
}

Received June 22, 2019; Accepted November 8, 2019

DOI: $10.3892 /$ ijo.2020.4954

\begin{abstract}
Plant flavonoid 2',3,4',5,7-pentahydroxyflavone (morin hydrate), isolated from the family Moraceae (Morus alba L.), is known to have anti-inflammatory and anticancer effects. However, its pharmaceutical effects on metastasis have not been fully elucidated to date. Therefore, the current study investigated the effects of morin hydrate on cancer metastasis in MCF-7 human breast cancer cells. The results showed that morin hydrate suppressed 12-O-tetradecanoylphorbol-13-acetate (TPA)-indu ced cell migration and invasion via the inhibition of matrix metalloproteinase (MMP)-9 activity. Furthermore, gene expression level of MMP-9, MMP-7, urokinase plasminogen activator (uPA), uPA receptor (UPAR) and fibronectin were significantly decreased by morin hydrate treatment. Morin hydrate inhibited the phosphorylation of Akt and glycogen synthase kinase (GSK)-3 $\beta$, and downregulated the expression of an activator protein- 1 subunit c-Fos. In addition, the GSK-3 $\beta$ phosphorylation and c-Fos expression were suppressed by PI3K/Akt pathway inhibitors, LY294002 and wortmannin. Taken together, these results demonstrated that morin hydrate reduced the metastatic potential in TPA-treated MCF-7 human breast cancer cells via the inhibition of MMPs, uPA and uPAR, and the underlying Akt/GSK-3 $\beta / \mathrm{c}-F o s$ pathway. Therefore, the present investigation suggested that morin hydrate may be a natural substance with a preventive potential for metastasis in breast cancer cells.
\end{abstract}

\section{Introduction}

Although advanced techniques are being developed to treat breast cancer, which is the most common cancer among

Correspondence to: Professor Kyung-Soo Nam, Department of Pharmacology, School of Medicine and Intractable Disease Research Center, Dongguk University, Gyeongju, Gyeongsangbuk 38066, Republic of Korea

E-mail:namks@dongguk.ac.kr

Key words: morin hydrate, metastasis, Akt, glycogen synthase kinase- $3 \beta$, breast cancer women, its mortality is still steadily increasing each year (1). Previous studies demonstrated that mortality was closely associated with metastasis: The 5-year survival rate of breast cancer patients diagnosed with non-metastasized tumor was $\geq 90 \%$, while the survival rate of metastatic breast cancer patients was $27 \%(2,3)$. Therefore, it is necessary to understand the mechanism of metastasis in cancer to improve the 5 -year survival rate and lower the risk of recurrence.

Metastasis entails a number of complex steps, including detachment of primary cancer cells, migration, invasion, and attachment of detached cancer cells at secondary sites (4). During these steps, matrix metalloproteinases (MMPs), urokinase plasminogen activator (UPA), and UPA receptor (UPAR) play important roles in the degradation of extracellular matrix (ECM) and basement membrane $(5,6)$. Among MMPs, MMP-9 plays an important role in breast cancer metastasis. Several investigations have revealed the relationship between the MMP-9 level and metastasis in breast cancer patients or breast cancer cell models (6-10). Certain studies observed a high metastatic potential in MMP-9-overexpressing breast cancer cells $(11,12)$. Furthermore, other researchers demonstrated that the inhibition of MMP-9 expression decreased the metastatic potential in breast cancer cells, implicating that the inhibition of MMP-9 expression may be a useful strategy for the prevention of metastasis in breast cancer $(7,13)$. uPA, which activates MMP-9 and degrades ECM and BM via catalyzing plasmin production, is also a key proteolytic enzyme for breast cancer metastasis (6). Furthermore, certain clinical studies showed that the prognosis and recurrence rate of breast cancer were linked with the uPA level in tumor tissue or serum, indicating that uPA is an important prognostic factor in breast cancer $(5,14,15)$. Taken together, these previous studies demonstrated that the monitoring of MMP-9 and uPA is an important strategy for the prevention of metastasis in breast cancer.

A number of studies demonstrated that the metastatic potential in various cancer models was predominantly linked with the transcriptional regulation of MMP-9 and uPA, mediated by activator protein-1 (AP-1) and/or NF- $\mathrm{B}(16,17)$. Furthermore, several investigations revealed that natural substances and/or chemicals reversed the 12-O-tetradecanoylphorbol-13-acetate (TPA)-induced metastatic potential via the regulation of 
MMP-9 and/or uPA expression through the regulation of c-Jun and/or c-Fos expression in breast cancer cells $(7,18,19)$. These investigations imply that AP-1 is an important transcription factor for the regulation of MMP-9 and UPA expression in breast cancer cells.

Fibronectin plays an important role in MMP-9 secretion and is a potent marker of poor breast cancer prognosis $(20,21)$. When cancer cells are released from the primary tumor and invade other tissues, several proteases, such as MMP-9, uPA, UPAR and MMP-7, are involved in this process. Fibronectin participates in metastasis via stimulating MMP-9 secretion and increasing the metastatic potential (22-27). Furthermore, migration and invasion of MCF-7 cells were triggered by fibronectin treatment with the EMT-like morphological change (20). The aforementioned investigations demonstrate the importance of fibronectin in the regulation of metastatic potential in cancer.

Plant flavonoid 2',3,4',5,7-pentahydroxyflavone (morin hydrate), naturally occurring in almonds, bilberries, Moraceae family and leaves of Cudranaia tricuspidata Buread, has various physiological properties, including antihypertensive, antiangiogenic, hepatoprotective, and anti-inflammatory activities (28-30). However, the physiological activity of morin hydrate in hormone receptor-positive breast cancer has not been fully elucidated to date. The current study investigated the effects of morin hydrate on the TPA-induced metastatic potential in MCF-7 hormone receptor-positive human breast cancer cells.

\section{Materials and methods}

Materials. Morin hydrate, bicinchoninic acid (BCA) solution, TPA, hematoxylin, eosin, and sulforhodamine B (SRB) were purchased from Sigma-Aldrich; Merck KGaA. DMEM, insulin solution, trypsin and antibiotic/antimycotic solution were acquired from Welgene, Inc. Trichloroacetic acid (TCA) was purchased from Samchun Pure Chemical Co., Ltd., and $30 \%$ polyacrylamide solution, protease inhibitor cocktail, and phosphatase inhibitor cocktail were obtained from GenDEPOT. Primary antibodies for Akt (cat. no. 4691), phospho-Akt (cat. no. 4060), ERK1/2 (cat. no. 4695), phospho-ERK1/2 (cat.no.4370), JNK (cat.no.9258), phospho-JNK (cat.no.4668), p38 mitogen-activated protein kinase (MAPK; cat. no. 8690), phospho-p38 MAPK (cat. no. 4511), NF-кB (cat. no. 8242), phospho-NF- $\mathrm{B}$ (cat. no. 3033), c-Jun (cat. no. 9165), c-Fos (cat. no. 2250), glycogen synthase kinase (GSK)-3 $\beta$ (cat. no. 5676), phospho-GSK-3 $\alpha / \beta$ (cat. no. 9331) and GAPDH (cat. no. 5174) were purchased from Cell Signaling Technology, Inc., and goat anti-rabbit immunoglobulin G-horseradish peroxidase-conjugated antibody (cat. no. 31460) was from Thermo Fisher Scientific, Inc. PI3K/Akt inhibitors LY294002 and wortmannin were obtained from LC Laboratories and Cayman Chemical Company, respectively. Primers for reverse transcription-quantitative PCR (RT-qPCR) were synthesized by Bioneer Corporation.

Cell culture. MCF-7 human breast cancer cells were obtained from the Korean Cell Line Bank. The cells were grown in DMEM supplemented with 10\% FBS (American Type Culture Collection), $10 \mu \mathrm{g} / \mathrm{ml}$ insulin and $1 \%$ antimycotic/antibiotic mixture at $37^{\circ} \mathrm{C}$ in $5 \% \mathrm{CO}_{2}$ atmosphere. The cells were serum-starved for $24 \mathrm{~h}$ prior to the addition of conditioned DMEM containing morin hydrate $(0-200 \mu \mathrm{M})$ and/or $100 \mathrm{nM}$ TPA at $37^{\circ} \mathrm{C}$ in $5 \% \mathrm{CO}_{2}$ atmosphere. All cell culture experiments were performed at $37^{\circ} \mathrm{C}$ in a $5 \% \mathrm{CO}_{2}$ atmosphere in DMEM.

Analysis of cytotoxic effect of morin hydrate. A total of 5,000 cells were seeded into a 96-well plate in each well and attached for $24 \mathrm{~h}$ in DMEM supplemented with $10 \% \mathrm{FBS}$. Then, DMEM supplemented with $10 \%$ FBS in each well was replaced with conditioned DMEM containing 5\% FBS and various concentration of morin hydrate. The cells were further incubated for 24,48 or $72 \mathrm{~h}$; then the conditioned DMEM was removed. The cells were fixed with 20\% TCA solution for $1 \mathrm{~h}$, washed with tap water, and dried for $2 \mathrm{~h}$, all at room temperature. To stain the dried cells, $0.4 \%$ SRB solution was added into each well and stored at room temperature for $30 \mathrm{~min}$. The stained cells were rinsed with $1 \%$ acetic acid and dried at room temperature. Then, $100 \mu \mathrm{l}$ of $10 \mathrm{mM}$ Tris- $\mathrm{HCl}$ (pH 5.0) buffer was added in each well to dissolve SRB, and absorption was measured at a wavelength of $510 \mathrm{~nm}$ by a SpectraMax ${ }^{\circledR}$ M2e microplate reader (Molecular Devices, LLC).

Wound healing cell migration assay. A total of $5 \times 10^{5}$ cells/well were seeded into collagen-coated six-well plates and attached for $24 \mathrm{~h}$ in DMEM supplemented with $10 \%$ FBS. Then, the cell monolayers were scratched by $1 \mathrm{ml}$ micropipette tip and DMEM supplemented with $10 \%$ FBS was removed by aspiration. Then, the cell monolayers were washed by PBS to remove detached cells and serum-starved for $24 \mathrm{~h}$ in serum-free DMEM. Then, serum-free DMEM was removed and the cell monolyers were treated with various concentration of morin hydrate dissolved in DMEM containing 1\% FBS for $1 \mathrm{~h}$ prior to taking photographs. Then, the cells were further administrated with TPA to trigger cell migration for $24 \mathrm{~h}$ and the scratch zones were observed and photographed. The change of the width of the scratch zone was observed and images were captured with Nikon light microscope (Nikon Corporation).

Matrigel invasion assay. A total of $3 \times 10^{4}$ cells were plated in the upper chambers of 24 -well transwell plates $(8-\mu \mathrm{m}$-pore; Corning Inc.) in cold serum-free DMEM. For the invasion assay, plates were coated with the Matrigel ${ }^{\circledR}$ (BD Biosciences) for $1 \mathrm{~h}$. DMEM supplemented $10 \%$ FBS were added in the lower chambers; then, the cells were cultured for $24 \mathrm{~h}$ in the upper chamber. The media in the upper chambers were replaced with serum-free DMEM and various concentrations of morin hydrate. The media in lower chambers were replaced with new DMEM supplemented with $10 \%$ FBS. After $1 \mathrm{~h}$, TPA was added into the upper chambers as an inducer for invasion. The cells were further incubated for $24 \mathrm{~h}$ at $37^{\circ} \mathrm{C}$ in $5 \% \mathrm{CO}_{2}$ atmosphere. The cells that migrated through or invaded the polycarbonate filter were fixed with $100 \%$ methanol and stained with heamatoxylin and eosin Y solution for $10 \mathrm{~min}$. The stained cells were observed with light microscope and images were captured using an inverted optical microscope. ImageJ (version 1.6.0_20) was used for data analysis (National Institutes of Health). 
Analysis of MMP-9 activity by gelatin zymography. A total of $5 \times 10^{5}$ cells/well were attached for $24 \mathrm{~h}$ and then further cultured for $24 \mathrm{~h}$ in FBS-free DMEM for serum-starvation. The cells were treated with various concentrations of morin hydrate with $100 \mathrm{nM}$ TPA for $24 \mathrm{~h}$. The DMEM were electrophoresed with $8 \%$ non-denaturing SDS-PAGE containing $0.1 \%(\mathrm{v} / \mathrm{v})$ gelatin. The gel was washed with $0.25 \%$ Triton X-100 solution to remove SDS and incubated at $37^{\circ} \mathrm{C}$ in a reaction buffer [5 $\mathrm{mM} \mathrm{CaCl}_{2}, 0.04 \% \mathrm{NaN}_{3}$ and $50 \mathrm{mM}$ Tris- $\mathrm{HCl}$ ] overnight to confirm the gelatinase activity of MMP-9. Bands were visualized by Coomassie brilliant blue $\mathrm{R}$ staining for $1 \mathrm{~h}$ and images were captured with LAS-4000 image analyzer (Fujifilm). ImageJ was used for data analysis.

Analysis of the change of nuclear c-Fos level by PI3K/Akt inhibitors. A total of $5 \times 10^{5}$ cells/well were attached for $24 \mathrm{~h}$ and then further cultured for $24 \mathrm{~h}$ in FBS-free DMEM for serum-starvation. The cells were pretreated for $24 \mathrm{~h}$ with various concentrations of morin hydrate and further incubated with or without Akt inhibitors, LY294002 $(20 \mu \mathrm{M})$ and wortmannin $(20 \mu \mathrm{M})$, for $30 \mathrm{~min}$ prior to TPA treatment for $1 \mathrm{~h}$ at $37^{\circ} \mathrm{C}$. Then, the cells were harvested and analyzed by western blotting.

RNA isolation and RT-qPCR. The cells were treated with morin hydrate and $100 \mathrm{nM}$ TPA for $24 \mathrm{~h}$ after 24-h attachment and 24-h serum-starvation. To isolate total RNA, the cells were harvested by trypsinization, collected by centrifugation at room temperature for $3 \mathrm{~min}$ at $1,000 \mathrm{x} \mathrm{g}$ and lysed with easy-BLUE ${ }^{\mathrm{TM}}$ Total RNA Extraction kit (Intron Biotechnology, Inc.). The extraction of total RNA from the lysed cells was performed in accordance with the manufacturer's protocol. Total RNA $(1 \mu \mathrm{g})$ was used for cDNA synthesis. RT reaction was performed to synthesize cDNA in $1 \mathrm{X} \mathrm{GoScript}{ }^{\mathrm{TM}}$ reaction buffer containing $2 \mathrm{mM} \mathrm{MgCl}_{2}$ with GoScript Reverse Transcriptase, $0.5 \mathrm{mM}$ dNTPs (Promega Corporation) and $\mathrm{pd}(\mathrm{N}) 9$ Random Primers (Takara Bio, Inc.). qPCR was performed using Q Green Sybr Green Master Mix kit (CellSafe Co., Ltd.) using Eco ${ }^{\mathrm{TM}}$ Real-Time PCR system (Illumina, Inc.). The following thermocycling conditions were used: Initial denaturation at $95^{\circ} \mathrm{C}$ for $5 \mathrm{~min} ; 45$ cycles of $95^{\circ} \mathrm{C}$ for $10 \mathrm{sec}, 60^{\circ} \mathrm{C}$ for $20 \mathrm{sec}$ and $72^{\circ} \mathrm{C}$ for $20 \mathrm{sec}$. Relative mRNA expression was automatically calculated using EcoStudy software (version 5.0.49; Illumina, Inc.). The primer sequences for PCR amplification are presented in Table I.

Nuclear fractionation. A total of $5 \times 10^{5}$ cells/well were attached for $24 \mathrm{~h}$ and then further cultured for $24 \mathrm{~h}$ in FBS-free DMEM for serum-starvation. The cells were pretreated with or without morin hydrate for $24 \mathrm{~h}$ and then further incubated with or without TPA for $1 \mathrm{~h}$ with serum-free DMEM. Then, DMEM was removed, the cells were washed twice with ice-cold PBS and treated with a hypotonic buffer $(20 \mathrm{mM}$ Tris- $\mathrm{HCl} \mathrm{pH} \mathrm{7.4,}$ $10 \mathrm{mM} \mathrm{NaCl}$ and $3 \mathrm{mM} \mathrm{MgCl}$ ) containing phosphatase and protease inhibitor cocktails. The cells were collected using a rubber policeman scraper, transferred to new microtubes and incubated for $15 \mathrm{~min}$ on ice. Then, $1 / 8$ vol 10\% NP-40 (Sigma-Aldrich; Merck KGaA) was added and the cells were vortexed for $10 \mathrm{sec}$ at the highest speed setting. The cells were incubated on ice for $10 \mathrm{~min}$ and centrifuged at 2,500 $\mathrm{x} \mathrm{g}$ for
$10 \mathrm{~min}$ at $4^{\circ} \mathrm{C}$. The supernatants were removed as the cytosolic fraction, and the pellet was lysed for $30 \mathrm{~min}$ on ice with the Cell Extraction Buffer (Invitrogen; Thermo Fisher Scientific, Inc.) containing phosphatase and protease inhibitor cocktails. The lysates were separated by centrifugation at $14,000 \times \mathrm{xg}$ for $30 \mathrm{~min}$ at $4^{\circ} \mathrm{C}$ and the supernatants were removed as the nuclear fraction.

Western blotting. A total of $5 \times 10^{5}$ cells/well were attached for $24 \mathrm{~h}$ and then further cultured for $24 \mathrm{~h}$ in FBS-free DMEM for serum-starvation. The cells were pretreated with or without morin hydrate for $24 \mathrm{~h}$ and then further incubated with or without TPA for 30 min with serum-free DMEM. Then,DMEM was removed, the cells were washed twice with ice-cold PBS, and whole cell lysates were prepared with radioimmunoprecipitation assay lysis buffer (Biosesang) supplemented with protease inhibitor and phosphatase inhibitor cocktails. The lysed cells were centrifuged at $14,000 \mathrm{x}$ g for $10 \mathrm{~min}$ at $4^{\circ} \mathrm{C}$, and the supernatants were collected as the whole cell lysate and stored at $-80^{\circ} \mathrm{C}$ until further use. Equal amounts $(20 \mu \mathrm{g})$ of protein form the whole cell lysate, nuclear fraction or cytosolic fraction were subjected to 8 or $10 \%$ SDS-PAGE and transferred to PVDF membranes (Pall Life Sciences). Blocking was performed with $5 \%$ non-fat dry milk or $1 \%$ bovine serum albumin (BSA; Santa CruzBiotechnology,Inc.) in Tris-buffered saline-Tween (TBST; $50 \mathrm{mM}$ Tris- $\mathrm{HCl}, 150 \mathrm{mM} \mathrm{NaCl}$, $0.1 \%$ Tween-20) solution for $1 \mathrm{~h}$ at room temperature. The primary antibodies for target proteins were diluted at 1:3,000 in 5\% non-fat dry milk or $1 \%$ BSA in TBST solution, and the reactions for primary antibodies were conducted overnight at $4^{\circ} \mathrm{C}$. Subsequently, the membrane was washed by TBST solution, covered with secondary antibody diluted at 1:5,000 in TBS solution and incubated for $1 \mathrm{~h}$ at room temperature. The target protein bands were detected by a chemiluminescent substrate $[100 \mathrm{mM}$ Tris ( $\mathrm{pH}$ 8.5; BioShop Canada, Inc.), $1.25 \mathrm{mM}$ luminol, $198 \mu \mathrm{M}$ coumaric acid and $0.01 \%$ hydrogen peroxide (all Sigma-Aldrich; Merck KGaA)] and images were captured using LAS-4000 image analyzer. The band densities were analyzed with Scion Image software (Alpha 4.0.3.2; Scion Corporation).

Statistical analysis. Data were analyzed using one-way ANOVA followed by Turkey post hoc test, using SPSS software (version 20.0; IBM Corp.). The values are presented as the mean $\pm \mathrm{SD}$. $\mathrm{P}<0.05$ was considered to indicate a statistically significant difference.

\section{Results}

Effect of morin hydrate on MCF-7 human breast cancer cell viability. Previous studies showed that morin hydrate had no cytotoxic activity in KEL FIB human fibroblast cells and EA.hy 926 human umbilical endothelial cells $(31,32)$. Therefore, the current study firstly tested the effects of morin hydrate on cell viability in MCF-7 human breast cancer cells using an SRB colorimetric assay. MTT assay was not used, as the absorbance of insoluble formazan produced by MTT reagents is affected by morin hydrate. The result of the current study showed that cell viability of MCF-7 cells was slightly decreased after treatment with $0-200 \mu \mathrm{M}$ morin hydrate and the maximum 
Table I. Nucleotide sequences for primers used in quantitative PCR.

Target

Reverse

Primer sequence $\left(5^{\prime}-3^{\prime}\right)$

Forward

CAGTGGGAGACCTCGAGAAG
GGGACTCCTACCCATTTG
GGGACGCAGACATCGTCATC
GGAGATGAAGTTTGAGGTGG
CACAAAACTGCCTCCTTCCT
CGACCCAACCCAAGAATCTA
TGAGCCTGAAGCCAACCTTA
CTGCTCCTCCTGTTCGACAGT

CAGTGGGAGACCTCGAGAAG

GGGACTCCTACCCATTTG

GGGACGCAGACATCGTCATC

GGAGATGAAGTTTGAGGTGG

CGACCCAACCCAAGAATCTA

CTGCTCCTCCTGTTCGACAGT
Fibronectin

MMP-7

MMP-9

UPA

UPAR

E-cadherin

$\mathrm{N}$-cadherin

GAPDH

TCCCTCGGAACATCAGAAAC
CAGCGTTCATCCTCATCG
TCGTCATCGTCGAAATGGGC
GGTCTGTATAGTCCGGGATG
AATCCCCGTTGGTCTTACAC
AGGCTGTGCCTTCCTACAGA
AGGTCCCCTGGAGTTTTCTG
CCGTTGACTCCGACCTTCAC

MMP, matrix metalloproteinase; uPA, urokinase plasminogen activator; uPAR, uPA receptor.
A

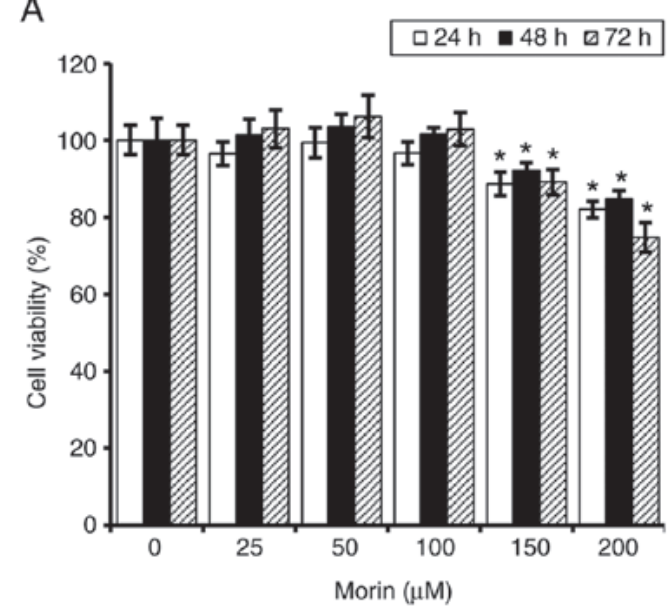

B

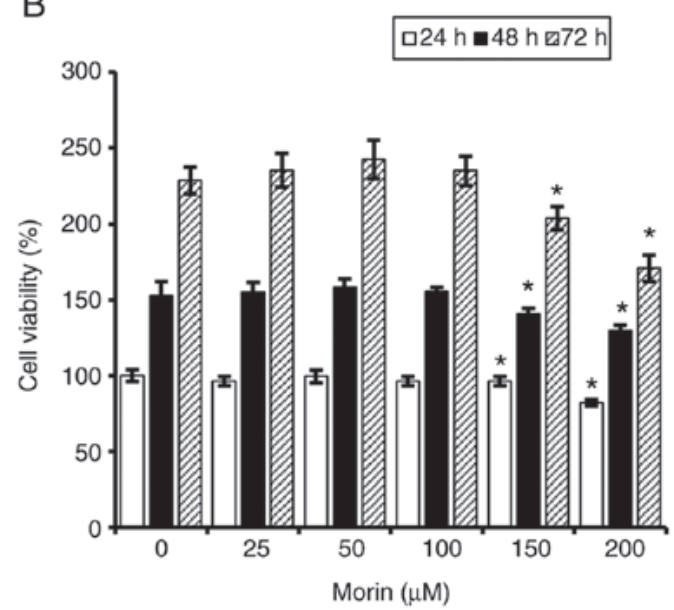

Figure 1. Viability of MCF-7 cells is slightly decreased by morin hydrate. Cell viabilities were measured at 24,48 and 72 h after treatment with various concentration of morin hydrate. Sulforhodamine B method was used for the assessment of cytotoxic activity of morin hydrate. The same data were presented in a different manner to confirm whether the change of cell viability was caused by cell death. (A) Cell viabilities were analyzed to determine whether the change of cell viabilities was caused by cell growth inhibition without cell death. Cell viabilities at 24,48 and $72 \mathrm{~h}$ were compared with $0 \mu \mathrm{M}$ morin hydrate-treated sample. (B) Each cell viability was compared with $0 \mu \mathrm{M}$ morin hydrate-treated sample at $24 \mathrm{~h}$. Three independent experiments were performed. Data are presented as the mean $\pm \mathrm{SD}$. ${ }^{*} \mathrm{P}<0.05$ vs. $0 \mu \mathrm{M}$ morin hydrate.

reduction rate of $>20 \%$ was observed after treatment with $200 \mu \mathrm{M}$ morin hydrate for $72 \mathrm{~h}$ (Fig. 1A). Furthermore, the reduction of cell viability was associated with the delayed cell growth (Fig. 1B). These results suggested that morin hydrate had a weak antiproliferative activity when administered at a concentration range of 150-200 $\mu \mathrm{M}$ in MCF-7 hormone receptor-positive human breast cancer cells.

Effect of morin hydrate on TPA-induced migration and invasion of MCF-7 human breast cancer cells. The current study assessed whether morin hydrate could prevent TPA-induced metastatic potential in MCF-7 human breast cancer cells using cell migration and invasion assays. The result showed that TPA-enhanced cell migration was decreased by morin hydrate treatment in a concentration-dependent manner (Fig. 2A and C). Furthermore, the invasiveness promoted by TPA was also reversed by the presence of morin hydrate in MCF-7 cells in a concentration-dependent manner
(Fig. 2B and D). These results suggest that morin hydrate could suppress the TPA-induced metastatic potential in MCF-7 cells.

Effect of morin hydrate on metastatic factors in TPA-treated MCF-7 cells. As indicated above, morin hydrate decreased the invasiveness of MCF-7 cells induced by TPA. Therefore, the current study further evaluated the effects of morin hydrate on MMP-9 activity and expression levels of MMP-9, uPA, uPAR, fibronectin and MMP-7. According to the gelatin zymographic analysis, the proteolytic activity of MMP-9 enhanced by TPA was significantly suppressed by 150 and $200 \mu \mathrm{M}$ morin hydrate treatment in MCF-7 cells (Fig. 3A). Furthermore, MMP-9, uPA, UPAR and MMP-7 transcription levels were also decreased by morin hydrate supplementation in a concentration-dependent manner (Fig. 3B and C). In addition, gene expression of fibronectin, a known EMT factor, was significantly reduced by morin hydrate treatment (Fig. 3C). However, TPA did not affect the expression of E-cadherin and $\mathrm{N}$-cadherin which 
A

B
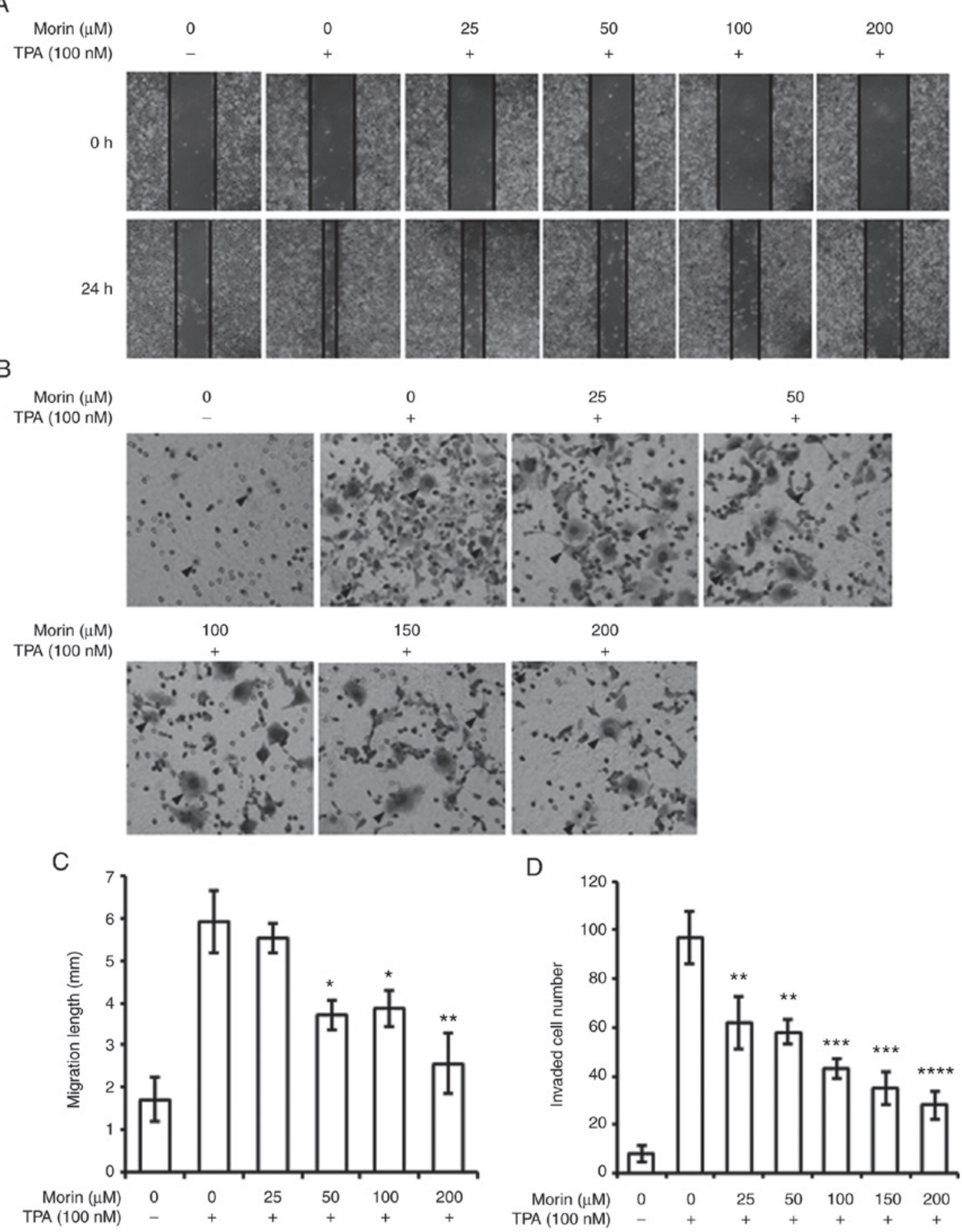

Figure 2. Migration and invasion of MCF-7 cells induced by TPA are reversed by morin hydrate. (A) Inhibition of cell migration by morin hydrate. Cell monolayers were scratched and serum-starved for $24 \mathrm{~h}$ and then scratch zones were observed as $0 \mathrm{~h}$ after pre-treatment with various concentration of morin hydrate for $1 \mathrm{~h}$ and further observed at $24 \mathrm{~h}$ after treating cells with or without TPA. Magnification, x40. (B) Inhibition of cell invasion by morin hydrate. Invasiveness was assessed at $24 \mathrm{~h}$ after treating cells with or without TPA and various concentrations of morin hydrate. Images of cells that invaded into the lower surface of the membrane were captured using Nikon DS-U3 Digital Sight microscope camera. Magnification, x100 (C) Four sections of scratched areas were randomly selected and the width of the wounds was measured by ImageJ. (D) The membranes were divided into four sections and the number invaded cells was counted by ImageJ. Small triangles indicate invaded cells. Three independent experiments were performed. Data are presented as the mean \pm SD. ${ }^{*} \mathrm{P}<0.05,{ }^{* *} \mathrm{P}<0.01,{ }^{* * *} \mathrm{P}<0.001$ and ${ }^{* * *} \mathrm{P}<0.0001$ vs. TPA only. TPA, 12-O-tetradecanoylphorbol-13-acetate.

are also EMT factors (data not shown). The results suggested that morin hydrate could prevent the participation of MMP-9 activity induced by TPA via negative regulation of MMP-9, uPA, uPAR, fibronectin and MMP-7.
Morin hydrate inhibits TPA-induced phosphorylation of Akt and GSK-3 $\beta$ and the expression of c-Fos. The current study evaluated the effects of morin hydrate on the phosphorylation levels of Akt, MAPK and GSK3 $\beta$, as well as on the expression 
A

Morin $(\mu \mathrm{M}) \quad 0 \quad 0 \quad 25 \quad 50 \quad 100 \quad 150 \quad 200$ TPA $(100 \mathrm{nM})-++\quad+\quad+$
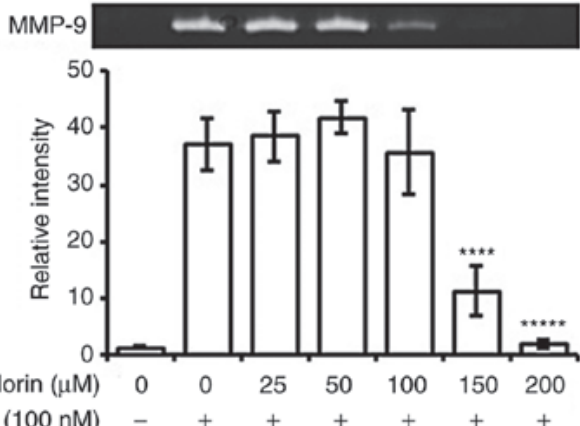

C
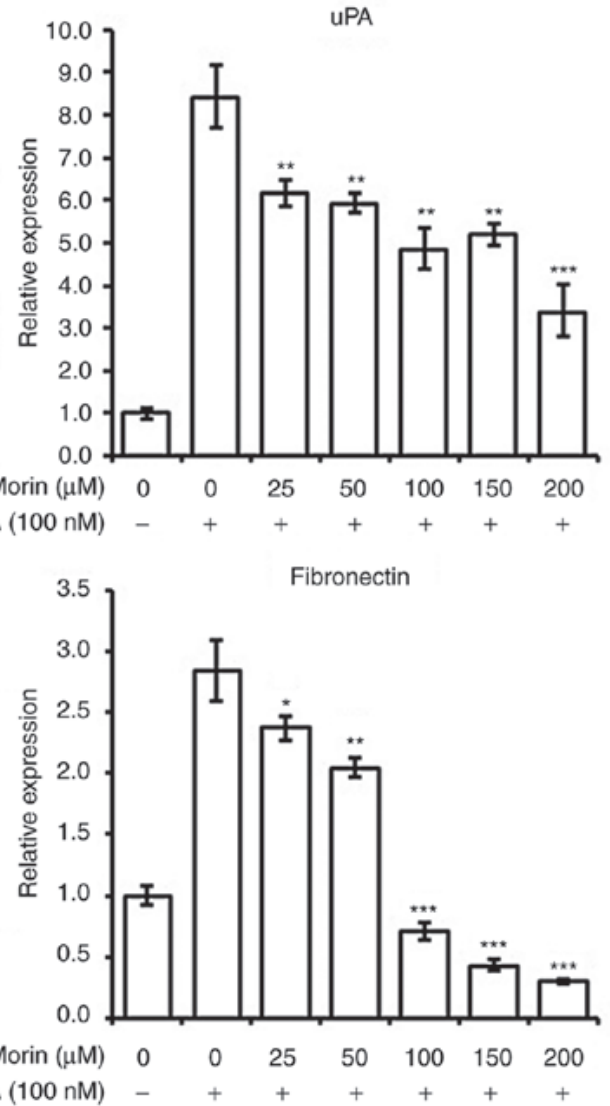

B
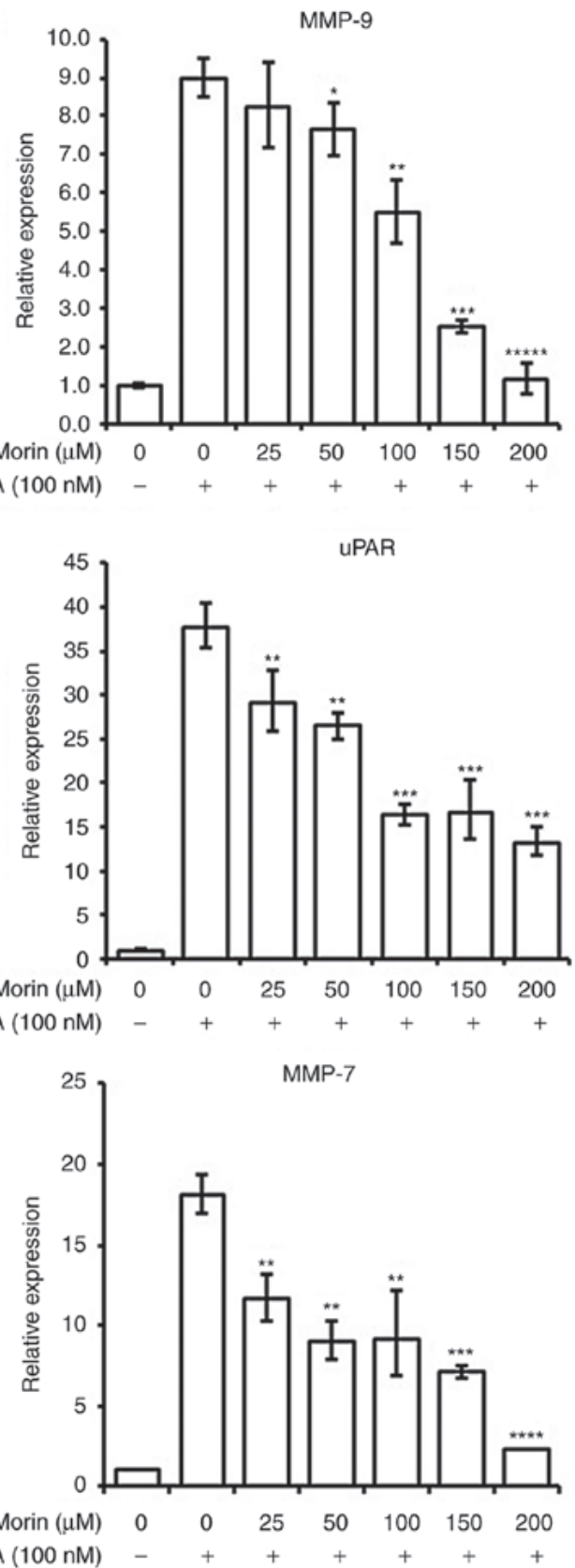

Figure 3. Morin hydrate inhibits MMP-9 activity and MMP-9 transcription induced by TPA. (A) Suppression of gelatinase activity of MMP-9 by morin hydrate. MMP-9 activity was induced by TPA for $24 \mathrm{~h}$ with or without morin hydrate. Conditioned DMEM was collected and subjected by $8 \%$ non-denaturing SDS-PAGE containing $0.1 \%$ gelatin. Clear bands images were captured with LAS-4000 image analyzer. (B) Morin hydrate-mediated downregulation of gene expression of metastasis-associated factors including (B) MMP-9 and (C) uPA, uPAR, fibronectin and MMP-7. GAPDH was used as the internal control. Three independent experiments were performed. Data are presented as the mean $\pm \mathrm{SD}$. ${ }^{*} \mathrm{P}<0.05,{ }^{* * *} \mathrm{P}<0.01,{ }^{* * *} \mathrm{P}<0.001,{ }^{* * * *} \mathrm{P}<0.0001$ and ${ }^{* * * * * *} \mathrm{P}<0.00001$ vs. TPA only. TPA, 12-O-tetradecanoylphorbol-13-acetate; MMP, matrix metalloproteinase; uPA, urokinase plasminogen activator; uPAR, uPA receptor.

levels of AP-1 subunits c-Jun and c-Fos. The result showed that morin hydrate suppressed the phosphorylation of Akt and GSK-3 $\beta$, in addition to the expression of c-Fos induced by TPA, in a concentration-dependent manner (Fig. 4A-C). By contrast, phosphorylation levels of ERK1/2 and NF- $\kappa \mathrm{B}$, and the expression of c-Jun, which are also involved in the regulation of expression of metastasis-enhancing factors, were not affected by morin hydrate treatment (Fig. 4C and D). JNK and p38 phosphorylation levels were also not altered by treatment with morin hydrate (data not shown). These results suggest that the inhibition of expression of metastasis-enhancing factors by morin hydrate may be associated with the reversal of Akt and GSK $3 \beta$ phosphorylation and inhibition of c-Fos expression.

Morin hydrate decreases the TPA-induced nuclear c-Fos level. Therefore, the current study assessed the effect of morin hydrate on the nuclear localization of c-Fos and c-Jun. Morin hydrate decreased the nuclear c-Fos level increased by TPA, in a concentration-dependent manner (Fig. 5A and B). However, the nuclear c-Jun level was not changed by morin hydrate treatment (Fig. 5A). These results imply that morin hydrate could inhibit AP-1 transcriptional activity by decreasing the c-Fos 

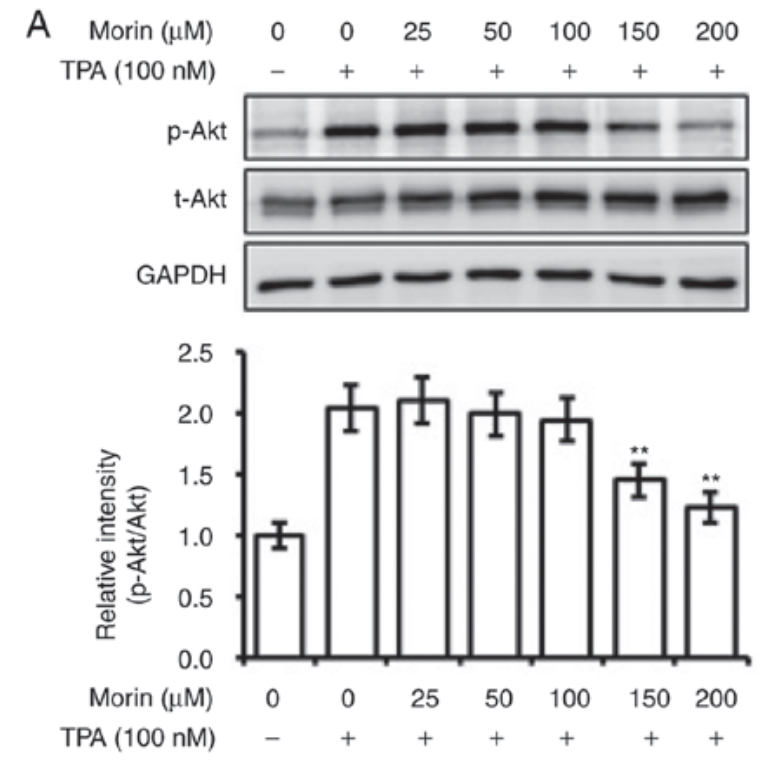

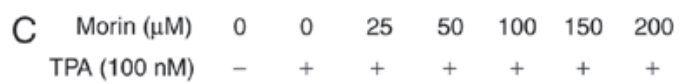
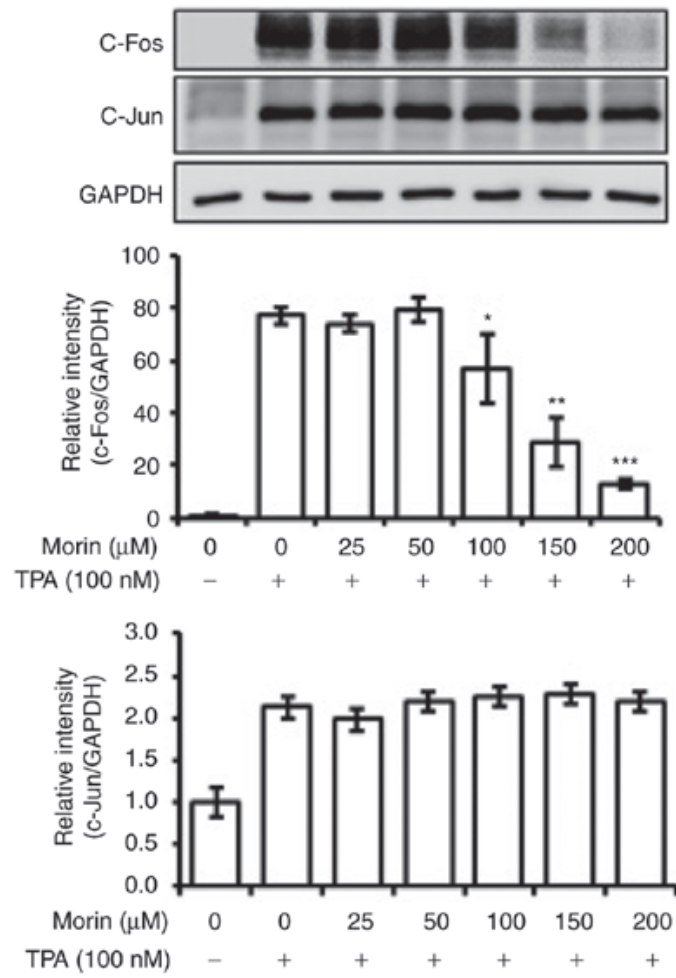
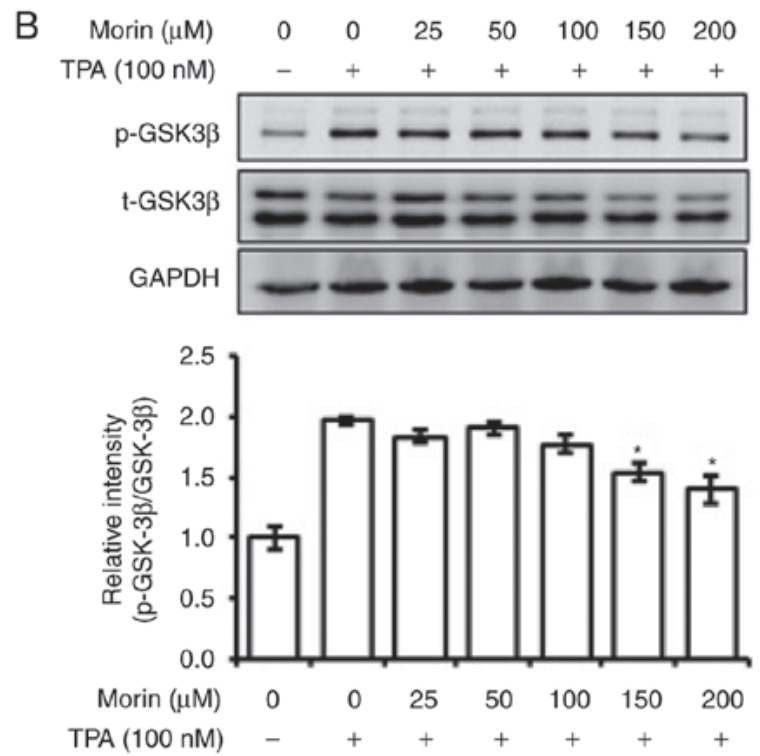

D $\begin{array}{rlllllll}\text { Morin }(\mu \mathrm{M}) & 0 & 0 & 25 & 50 & 100 & 150 & 200 \\ \operatorname{TPA}(100 \mathrm{nM}) & - & + & + & + & + & + & +\end{array}$
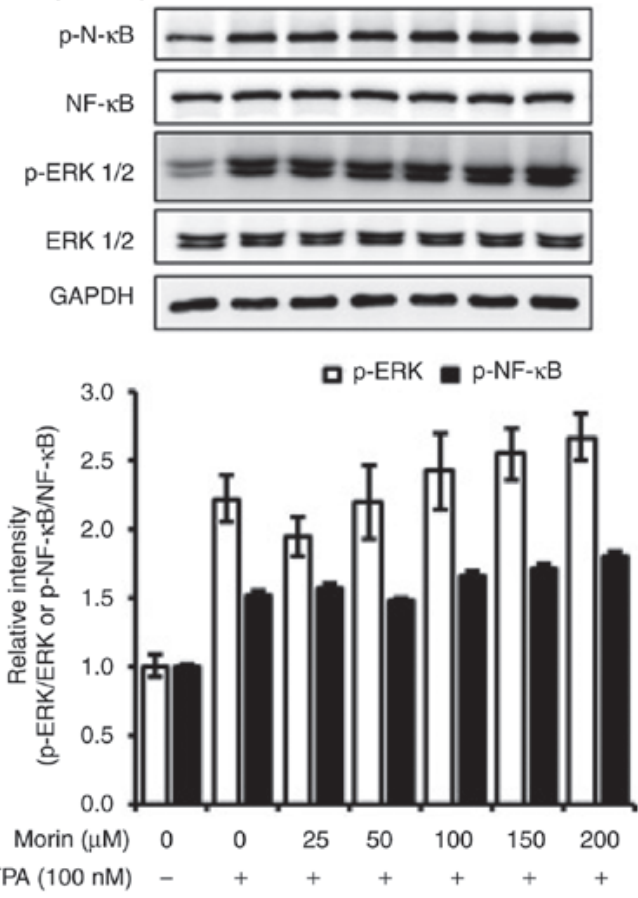

Figure 4. Morin hydrate reverses the phosphorylation of Akt and GSK-3 $\beta$ and inhibits the expression of c-Fos induced by TPA. (A) Reversal of TPA-induced Akt phosphorylation by morin hydrate. (B) Inhibition of TPA-induced GSK-3 $\beta$ phosphorylation by morin hydrate. (C) Suppression of TPA-induced c-Fos expression by morin hydrate. (D) Effect of morin hydrate on TPA-induced NF- $\kappa$ B and ERK $1 / 2$ phosphorylation. Whole cell lysates were prepared with radioimmunoprecipitation assay lysis buffer and then subjected by $10 \%$ SDS-PAGE. Bands were developed using a chemiluminescent substance and images were captured using an LSA-4000 image analyzer. GAPDH was used as an internal control. Three independent experiments were performed. Data are presented as the mean \pm SD. ${ }^{*} \mathrm{P}<0.05,{ }^{* *} \mathrm{P}<0.01,{ }^{* * *} \mathrm{P}<0.001$ vs. TPA only. TPA, 12-O-tetradecanoylphorbol-13-acetate; GSK, glycogen synthase kinase; p, phospho; t, total.

level in the nucleus. The change of the nuclear c-Fos level was also associated with altered whole cell c-Fos expression.

Akt inhibitors suppress GSK-3 $\beta$ phosphorylation and c-Fos expression. The results of the current study revealed that morin hydrate inhibited Akt and GSK-3 $\beta$ phosphorylation, and c-Fos expression (Fig. 6A), without the change of ERK and NF- $\kappa \mathrm{B}$ phosphorylation (Fig. 4D). Therefore, the current study tested the effects of PI3K/Akt inhibitors, LY294002 and wortmannin, on Akt and GSK-3 $\beta$ phosphorylation and c-Fos expressions. The PI3K/Akt inhibitors downregulated the TPA-induced Akt and GSK-3 $\beta$ phosphorylation as well as the c-Fos expression. These results suggested that the inhibitory effect of morin hydrate on the metastatic potential may be regulated by the inhibition of the PI3K/Akt-mediated GSK-3 $\beta$ phosphorylation and c-Fos expression (Fig. 6B). 
A

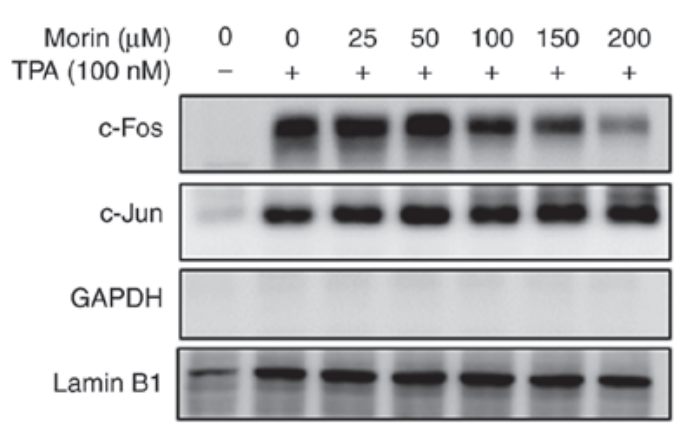

B

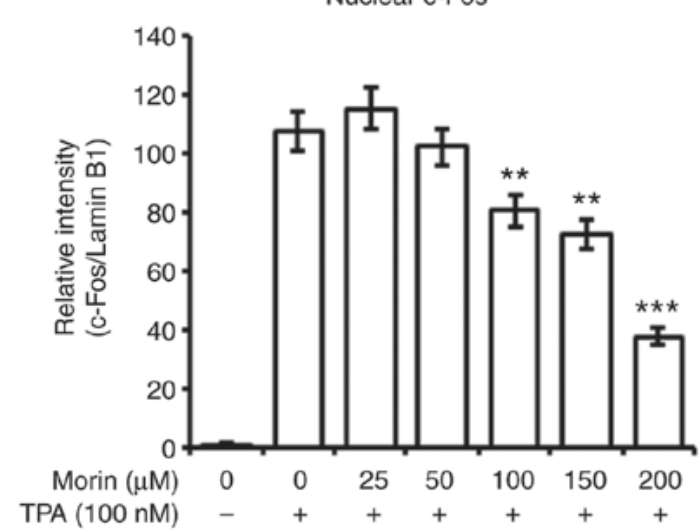

Cytosol

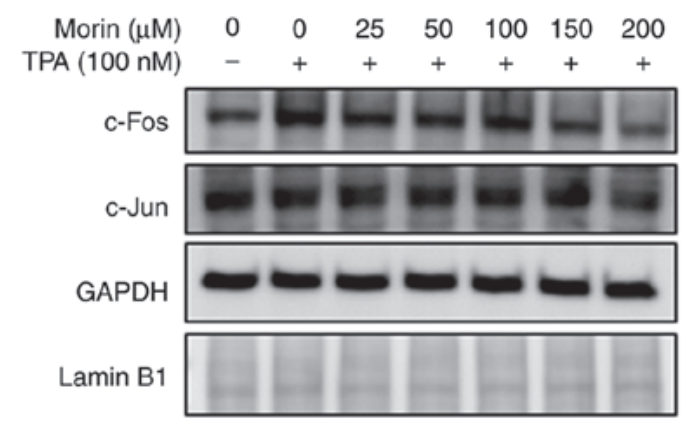

Cytosolic c-Fos

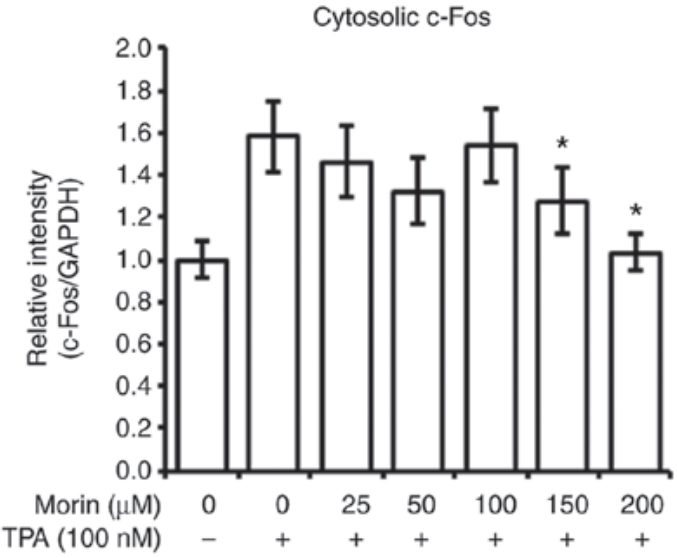

Figure 5. TPA-increased nuclear c-Fos level is decreased by morin hydrate. (A) Nuclear and cytosolic protein fractions were extracted and subjected to $10 \%$ SDS-PAGE. Bands were developed using a chemiluminescent substance and images were captured by LSA-4000 image analyzer. Lamin B1 and GAPDH was used as the internal controls for nuclear and cytosolic expression, respectively. Three independent experiments were performed. (B) Data are presented as the mean \pm SD. ${ }^{*} \mathrm{P}<0.05,{ }^{* *} \mathrm{P}<0.01$ and ${ }^{* * *} \mathrm{P}<0.001$ vs. TPA only. TPA, 12-O-tetradecanoylphorbol-13-acetate.

\section{Discussion}

Metastasis is one of the major causes of poor prognosis of patients with cancer. Therefore, prevention of metastasis is an important strategy for effective cancer therapy. Metastasis is primarily regulated by a number of factors, including MMPs, uPA and uPAR. Numerous investigations revealed that the inhibition of metastasis was linked with the regulation of MMPs, uPA and/or uPAR activities and/or expression levels $(5,6,18,33-35)$. In the present study, morin hydrate suppressed cell migration and invasiveness in TPA-treated MCF-7 human breast cancer cells, and delayed cell growth. Furthermore, MMP-9 activity was markedly decreased by morin hydrate. In addition, the expression levels of metastasis-enhancing factors, such as MMP-7, MMP-9, uPA, and uPAR, were decreased by morin hydrate, in a concentration-dependent manner. MMP-9 is a secretory protein activated by plasmin produced by the UPA/uPAR system, and its secretion is triggered by fibronectin $(21,36)$. MMP-9 activity is closely associated with its gene expression (13,35). In addition, Wang et al (37) reported that enhanced cell invasion and increased MMP-2 and MMP-9 secretion were shown in MMP-7-transfected MCF-7 cells, suggesting that MMP-7 participates in MMP-9 activation. In the present study, morin hydrate only reduced MMP-9 expression but also prevented MMP-9 activation and secretion via the inhibition of MMP-7, fibronectin, uPA and UPAR gene expression. Consequently, the results demonstrated that the inhibition of TPA-induced metastatic potential by morin hydrate in MCF-7 human breast cancer cells was linked with the downregulation of metastasis-enhancing factor expression and the diminishment of MMP-9 activity.

The expression of metastasis-enhancing factors, such as MMP-9, uPA and uPAR, is predominantly regulated by Akt and MAPK and involves the JNK, ERK, and p38 signaling pathways. GSK-3 $\beta$ is also a key protein involved in the EMT, Wnt signaling and metastasis in breast cancer (38). Furthermore, the activity of AP-1, which is an important transcription factor regulating MMP-9, uPA, and uPAR expression, is directly regulated by GSK-3 $\beta$ (39). Previous studies showed that enhanced migration of MCF-7 human breast cancer cells was mediated by the induction of GSK- $3 \beta$ phosphorylation $(40,41)$. These studies implied that the inhibition of metastatic potential was linked with the suppressive regulation of GSK-3 $\beta$ phosphorylation. In the current study, morin hydrate suppressed not only cell migration and invasion, but also the phosphorylation of GSK-3 $\beta$ induced by TPA in MCF-7 cells, in a concentration-dependent manner. A previous study revealed that the activation of protein kinase $\mathrm{C}$ (PKC) by TPA lead to the inactivation of GSK-3 $\beta$, inducing the activation of AP-1 and promotion of tumorigenesis (42). In the current study, morin hydrate inhibited the expression of AP-1 subunit c-Fos induced by TPA and this inhibition was associated with the inhibition of GSK-3 $\beta$ phosphorylation. Furthermore, nuclear 
A

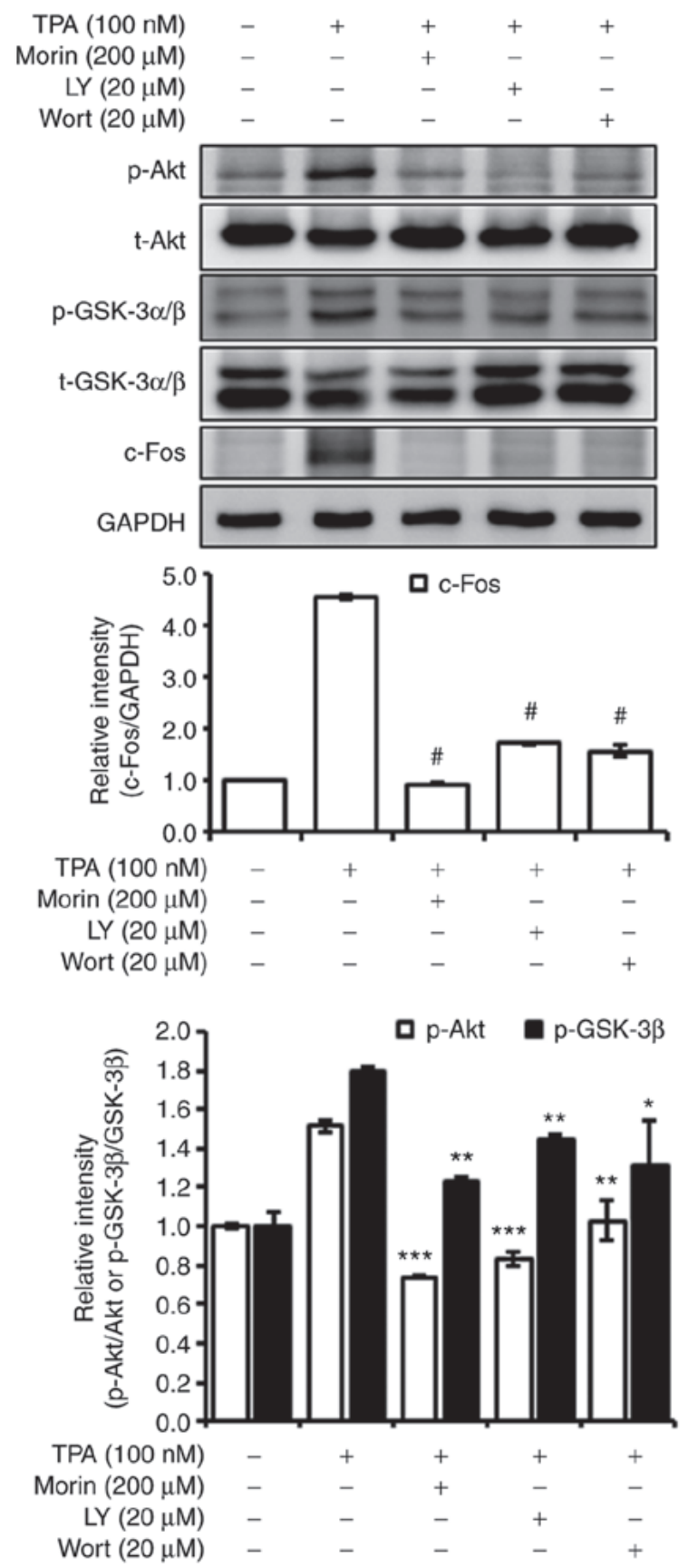

Figure 6. Decrease in nuclear c-Fos level by morin hydrate is regulated by the Akt-mediated signaling pathway. (A) Akt inhibitors, LY294002 and wortmannin, and morin hydrate, inhabited the phosphorylation of Akt and GSK-3 $\beta$ as well as the expression of c-Fos induced by TPA. The cells were pretreated with morin hydrate for $24 \mathrm{~h}$ and treated with Akt inhibitors, LY $(20 \mu \mathrm{M})$ and wort $(20 \mu \mathrm{M})$, for 30 min prior to TPA treatment for $1 \mathrm{~h}$ at $37^{\circ} \mathrm{C}$. The whole cell lysates were subjected to $10 \%$ SDS-PAGE. Bands were developed by a chemiluminescent substance and images were captured using LSA-4000 image analyzer. GAPDH was used as the internal control. Three independent experiments were performed. Data are presented as the mean $\pm \mathrm{SD}$. ${ }^{*} \mathrm{P}<0.05,{ }^{* * *} \mathrm{P}<0.01$, ${ }^{* * * *} \mathrm{P}<0.001$ and ${ }^{\#} \mathrm{P}<0.0001$ vs. TPA only. (B) Proposed mechanism of morin hydrate-mediated inhibition of TPA-induced expression of metastasis-enhancing factors. TPA, 12-O-tetradecanoylphorbol-13-acetate; GSK, glycogen synthase kinase. LY, LY294002; Wort, wortmannin; p, phospho; t, total; MMP, matrix metalloproteinase; uPA, urokinase plasminogen activator; uPAR, uPA receptor.

level of c-Fos was also markedly decreased by morin hydrate, in a concentration-dependent manner. Therefore, morin hydrate may attenuate the metastatic potential through the inhibition of metastasis-enhancing factors, such as MMP-9, UPA, and UPAR, via downregulation of AP-1 transcriptional activity and activation of GSK-3 $\beta$. Consequently, these results demonstrate that the suppressive effect of morin hydrate
B

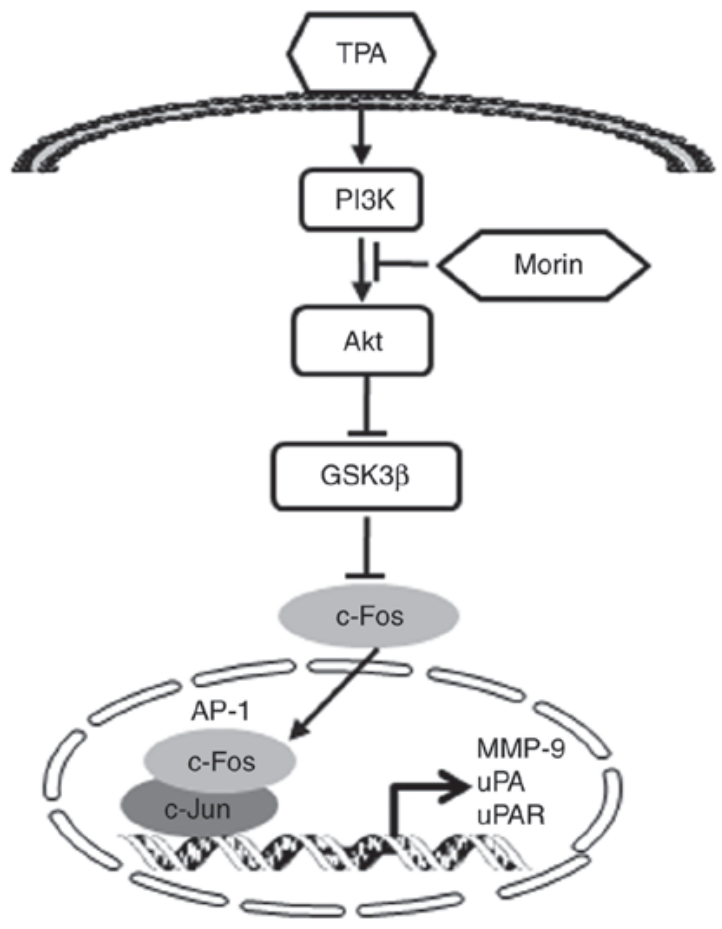


Akt (46). The present investigation showed that TPA-induced Akt phosphorylation was reversed by morin hydrate along with the suppression of GSK-3 $\beta$ phosphorylation, c-Fos expression, and nuclear c-Fos level. Furthermore, LY294002 and wortmannin, which are Akt/PI3K inhibitors, inhibited TPA-induced GSK-3 $\beta$ phosphorylation and c-Fos expression. By contrast, morin hydrate did not affect to phosphorylation of ERK and $N F-\kappa B$ induced by TPA. The transcriptional activity of AP-1 is closely linked with the nuclear localization of its subunits, c-Jun and c-Fos. These results demonstrated that the inhibition of TPA-induced metastatic potential by morin hydrate in MCF-7 cells was regulated via the Akt/GSK-3 $\beta / \mathrm{c}-$ Fos signaling pathway. Therefore, this investigation demonstrated that Akt acted as a key regulator of morin hydrate-mediated prevention of metastasis in MCF-7 human breast cancer cells.

The current study revealed the antimetastatic potential of morin hydrate in TPA-treated MCF-7 human breast cancer cells. This effect was shown at high concentrations (150-200 $\mu \mathrm{M})$ of morin hydrate. At doses of 150 and $200 \mu \mathrm{M}$, morin hydrate inhibited the growth of MCF-7 cells. Gene expression levels of metastatic factors, such as MMP-7, MMP-9, fibronectin, UPA and UPAR, were downregulated at lower morin hydrate concentrations (50-200 $\mu \mathrm{M}$ ); however, TPA-induced MMP-9 activity, Akt and GSK-3 $\beta$ phosphorylation and c-Fos expression were significantly reversed at 150 and $200 \mu \mathrm{M}$ morin hydrate. It may be hypothesized that the inhibition of metastatic potential by morin hydrate in TPA-treated MCF-7 cells was closely linked with the suppression of cell growth.

Although anticarcinogenic and anticancer activities of morin hydrate were previously evaluated in animal and cancer cells and no toxicity of morin hydrate (10 and $50 \mathrm{mg} / \mathrm{kg}$ ) was revealed in a mouse model following daily injection for 7 days, the effects of morin hydrate on metastasis remain to be fully assessed (30). The present investigation showed the antimetastatic activity of morin hydrate in TPA-treated MCF-7 cells and it was revealed that the antimetastatic potential was induced by the Akt/GSK-3 $\beta$-mediated inhibition of c-Fos expression. In conclusion, the present investigation demonstrated that morin hydrate, at the concentration range of $150-200 \mu \mathrm{M}$, is a potent substance that may prevent the metastasis of breast cancer. However, further research in patient-derived xenografts or $3 \mathrm{D}$ tumor models is required to assess the potential for clinical use.

\section{Acknowledgements}

Not applicable.

\section{Funding}

This research was supported by the Basic Science Research Program through the National Research Foundation of Korea funded by the Ministry of Education (grant no. 2018R1D1A1B07047758).

\section{Availability of data and materials}

The datasets used and/or analyzed during the current study are available from the corresponding author on reasonable request.

\section{Author's contributions}

KSL and KSN designed the experiments. KSL, GSN and JB performed experiments. KSL, SK and KSN analyzed the data. KSL wrote the manuscript. KSL, SK and KSN reviewed the manuscript. All authors confirmed and approved the final manuscript.

\section{Ethics approval and consent to participate}

Not applicable.

\section{Patient consent for publication}

Not applicable.

\section{Competing interests}

The authors declare that they have no competing interests.

\section{References}

1. Ghoncheh M, Pournamdar Z and Salehiniya H: Incidence and mortality and epidemiology of breast cancer in the world. Asian Pac J Cancer Prev 17: 43-46, 2016.

2. Howlader N, Noone AM, Krapcho M, Garshell J, Miller D, Altekruse SF, Kosary CL, Yu M, Ruhl J, Tatalovich Z, Mariotto A, et al: SEER Cancer Statistics Review, 1975-2012. National Cancer Institute. Bethesda, MD, 2015.https://seer.cancer. gov/archive/csr/1975_2012/. Accessed July 5, 2019.

3. Jung KW, Won YJ, Kong HJ, Oh CM, Cho H, Lee DH and Lee KH: Cancer statistics in Korea: Incidence, mortality, survival, and prevalence in 2012. Cancer Res Treat 47: 127-141, 2015.

4. Oskarsson T: Extracellular matrix components in breast cancer progression and metastasis. Breast 22 (Suppl 2): S66-S72, 2013.

5. Janicke F, Prechtl A, Thomssen C, Harbeck N, Meisner C, Untch M, Sweep CG, Selbmann HK, Graeff H, Schmitt M and German N0 Study Group: Randomized adjuvant chemotherapy trial in high-risk, lymph node-negative breast cancer patients identified by urokinase-type plasminogen activator and plasminogen activator inhibitor type 1. J Natl Cancer Inst 93: 913-920, 2001.

6. Kwon YS, Lee KS, Chun SY, Jang TJ and Nam KS: Suppressive effects of a proton beam on tumor growth and lung metastasis through the inhibition of metastatic gene expression in 4T1 orthotopic breast cancer model. Int J Oncol 49: 336-342, 2016.

7. Lee KS, Shin JS and Nam KS: Starfish polysaccharides downregulate metastatic activity through the MAPK signaling pathway in MCF-7 human breast cancer cells. Mol Biol Rep 40: 5959-5966, 2013

8. Li X, Kong X, Wang Y and Yang Q: BRCC2 inhibits breast cancer cell growth and metastasis in vitro and in vivo via downregulating AKT pathway. Cell Death Dis 4: e757, 2013.

9. Yang F, Hu M, Lei Q, Xia Y, Zhu Y, Song X, Li Y, Jie H, Liu C, Xiong Y, et al: Nifuroxazide induces apoptosis and impairs pulmonary metastasis in breast cancer model. Cell Death Dis 6: e1701, 2015.

10. Daniele A, Zito AF, Giannelli G, Divella R, Asselti M, Mazzocca A, Paradiso A and Quaranta M: Expression of metalloproteinases MMP-2 and MMP-9 in sentinel lymph node and serum of patients with metastatic and non-metastatic breast cancer. Anticancer Res 30: 3521-3527, 2010.

11. Choi JY, Jang YS, Min SY and Song JY: Overexpression of MMP-9 and HIF-1 $\alpha$ in breast cancer cells under hypoxic conditions. J Breast Cancer 14: 88-95, 2011.

12. Mehner C, Hockla A, Miller E, Ran S, Radisky DC and Radisky ES: Tumor cell-produced matrix metalloproteinase 9 (MMP-9) drives malignant progression and metastasis of basal-like triple negative breast cancer. Oncotarget 5: 2736-2749, 2014. 
13. Moirangthem A, Bondhopadhyay B, Mukherjee M, Bandyopadhyay A, Mukherjee N, Konar K, Bhattacharya S and Basu A: Simultaneous knockdown of uPA and MMP9 can reduce breast cancer progression by increasing cell-cell adhesion and modulating EMT genes. Sci Rep 6: 21903, 2016.

14. Harbeck N, Schmitt M, Kates RE, Kiechle M, Zemzoum I, Jänicke F and Thomssen C: Clinical utility of urokinase-type plasminogen activator and plasminogen activator inhibitor-1 determination in primary breast cancer tissue for individualized therapy concepts. Clin Breast Cancer 3: 196-200, 2002.

15. Look MP: Pooled analysis of UPA and PAI-1 for prognosis in primary breast cancer patients. EORTC receptor and biomarker study group. Int J Biol Markers 15: 70-72, 2000.

16. Sato H and Seiki M: Regulatory mechanism of $92 \mathrm{kDa}$ type IV collagenase gene expression which is associated with invasiveness of tumor cells. Oncogene 8: 395-405, 1993.

17. Takahra T, Smart DE, Oakley F and Mann DA: Induction of myofibroblast MMP-9 transcription in three-dimensional collagen I gel cultures: Regulation by NF-kappaB, AP-1 and Sp1. Int J Biochem Cell Biol 36: 353-363, 2004.

18. Kim HS, Kim MJ, Kim EJ, Yang Y, Lee MS and Lim JS Berberine-induced AMPK activation inhibits the metastatic potential of melanoma cells via reduction of ERK activity and COX-2 protein expression. Biochem Pharmacol 83: 385-394, 2012.

19. Kim S, Kim SH, Hur SM, Lee SK, Kim WW, Kim JS, Kim JH, Choe JH, Nam SJ, Lee JE and Yang JH: Silibinin prevents TPA-induced MMP-9 expression by down-regulation of COX-2 in human breast cancer cells. J Ethnopharmacol 126: 252-257, 2009.

20. Li CL, Yang D, Cao X, Wang F, Hong DY, Wang J, Shen XC and Chen Y: Fibronectin induces epithelial-mesenchymal transition in human breast cancer MCF-7 cells via activation of calpain. Oncol Lett 13: 3889-3895, 2017.

21. Thant AA, Nawa A, Kikkawa F, Ichigotani Y, Zhang Y, Sein TT, Amin AR and Hamaguchi M: Fibronectin activates matrix metalloproteinase-9 secretion via the MEK1-MAPK and the PI3K-Akt pathways in ovarian cancer cells. Clin Exp Metastasis 18: 423-428, 2000

22. Mierke CT, Frey B, Fellner M, Herrmann M and Fabry B: Integrin $\alpha 5 \beta 1$ facilitates cancer cell invasion through enhanced contractile forces. J Cell Sci 124: 369-383, 2011.

23. Nam JM, Onodera Y, Bissell MJ and Park CC: Breast cancer cells in three-dimensional culture display an enhanced radioresponse after coordinate targeting of integrin alpha5beta1 and fibronectin. Cancer Res 70: 5238-5248, 2010

24. Wei PL, Kuo LJ, Huang MT, Ting WC, Ho YS, Wang W, An J and Chang YJ: Nicotine enhances colon cancer cell migration by induction of fibronectin. Ann Surg Oncol 18: 1782-1790, 2011.

25. Kenny HA, Chiang CY, White EA, Schryver EM, Habis M, Romero IL, Ladanyi A, Penicka CV, George J, Matlin K, et al: Mesothelial cells promote early ovarian cancer metastasis through fibronectin secretion. J Clin Invest 124: 4614-4628, 2014.

26. Knowles LM, Gurski LA, Engel C, Gnarra JR, Maranchie JK and Pilch J: Integrin $\alpha v \beta 3$ and fibronectin upregulate Slug in cancer cells to promote clot invasion and metastasis. Cancer Res 73: 6175-6184, 2013.

27. Wang JP and Hielscher A: Fibronectin: How its aberrant expression in tumors may improve therapeutic targeting. J Cancer 8: 674-682, 2017.

28. Kang DG, Moon MK, Sohn EJ, Lee DH and Lee HS: Effects of morin hydrate on blood pressure and metabolic changes in fructose-induced hypertensive rats. Biol Pharm Bull 27: 1779-1783, 2004.

29. Jung HJ, Kim SJ, Song YS, Park EH and Lim CJ: Evaluation of the antiangiogenic, anti-inflammatory, and antinociceptive activities of morin hydrate. Planta Med 76: 273-275, 2010.
30. Lee HS, Jung KH, Park IS, Kwon SW, Lee DH and Hong SS: Protective effect of morin hydrate on dimethylnitrosamine-induced hepatic fibrosis in rats. Dig Dis Sci 54: 782-788, 2009.

31. Jin H, Lee WS, Eun SY, Jung JH, Park HS, Kim G, Choi YH, Ryu CH, Jung JM, Hong SC, et al: Morin hydrate, a flavonoid from Moraceae, suppresses growth and invasion of the highly metastatic breast cancer cell line MDA-MB-231 partly through suppression of the Akt pathway. Int J Oncol 45: 1629-1637, 2014.

32. Lee YJ, Kim WI, Kim SY, Cho SW, Nam HS, Lee SH and Cho MK: Flavonoid morin hydrate inhibits proliferation and induces apoptosis of melanoma cells by regulating reactive oxygen species, Sp1 and Mcl-1. Arch Pharm Res 42: 531-542, 2019.

33. Kim S, Chun SY, Lee DH, Lee KS and Nam KS: Mineral-enriched deep-sea water inhibits the metastatic potential of human breast cancer cell lines. Int J Oncol 43: 1691-1700, 2013.

34. Park SY, Kim YH, Kim Y and Lee SJ: Aromatic-turmerone attenuates invasion and expression of MMP-9 and COX-2 through inhibition of NF- $\mathrm{NB}$ activation in TPA-induced breast cancer cells. J Cell Biochem 113: 3653-3662, 2012.

35. Lee SO, Jeong YJ, Im HG, Kim CH, Chang YC and Lee IS: Silibinin suppresses PMA-induced MMP-9 expression by blocking the AP-1 activation via MAPK signaling pathways in MCF-7 human breast carcinoma cells. Biochem Biophys Res Commun 354: 165-171, 2007.

36. Li S, Lu J, Chen Y, Xiong N, Li L, Zhang J, Yang H, Wu C, Zeng $\mathrm{H}$ and Liu Y: MCP-1-induced ERK/GSK-3ß/Snail signaling facilitates the epithelial-esenchymal transition and promotes the migration of MCF-7 human breast carcinoma cells. Cell Mol Immunol 14: 621-630, 2017.

37. Wang Y and Zhou BP: Epithelial-mesenchymal transition-a hallmark of breast cancer metastasis. Cancer Hallm 1: 38-49, 2013.

38. Jin H, Yu Y, Zhang T, Zhou X, Zhou J, Jia L, Wu Y, Zhou BP and Feng Y: Snail is critical for tumor growth and metastasis of ovarian carcinoma. Int J Cancer 126: 2102-2111, 2010

39. Mishra R: Glycogen synthase kinase 3 beta: Can it be a target for oral cancer. Mol Cancer 9: 144, 2010.

40. Luo J: Glycogen synthase kinase 3 beta (GSK3 beta) in tumorigenesis and cancer chemotherapy. Cancer Lett 273: 194-200, 2009.

41. Weng CJ, Chau CF, Hsieh YS, Yang SF and Yen GC: Lucidenic acid inhibits PMA-induced invasion of human hepatoma cells through inactivating MAPK/ERK signal transduction pathway and reducing binding activities of NF-kappa B and AP-1. Carcinogenesis 29: 147-156, 2008.

42. Ma C, Wang J, Gao Y, Gao TW, Chen G, Bower KA, Odetallah M, Ding M, Ke Z and Luo J: The role of glycogen synthase kinase 3 beta in the transformation of epidermal cells. Cancer Res 67: 7756-7764, 2007.

43. Park SY, Kim YH, Kim Y and Lee SJ: Frondoside A has an anti-invasive effect by inhibiting TPA-induced MMP-9 activation via NF- $\mathrm{KB}$ and AP-1 signaling in human breast cancer cells Int J Oncol 41: 933-940, 2012.

44. Cross DA, Alessi DR, Vandenheede JR, McDowell HE, Hundal HS and Cohen P: The inhibition of glycogen-synthase kinase- 3 by insulin or insulin-like growth-factor 1 in the rat skeletal-muscle cell-line-L6 is blocked by wortmannin, but not by rapamycin: Evidence that wortmannin blocks activation of the mitogen-activated protein-kinase pathway in 16-cells between Ras and Raf. Biochem J 303: 21-26, 1994.

45. Cross DA, Alessi DR, Cohen P, Andjelkovich $M$ and Hemmings BA: Inhibition of glycogen-synthase kinase- 3 by insulin-mediated by protein-kinase B. Nature 378: 785-789, 1995 .

46. Kim J, Montagne K, Nemoto H, Ushida T and Furukawa KS: Hypergravity down-regulates c-fos gene expression via ROCK/Rho-GTP and the PI3K signaling pathway in murine ATDC5 chondroprogenitor cells. PLos One 12: e0185394, 2017. 